\title{
Performed Clinical Interpretation
}

National Cancer Institute

\section{Source}

National Cancer Institute. Performed Clinical Interpretation. NCI Thesaurus. Code C93425.

The completed assessment for determining the meaning of a clinical result. 